\title{
TRABALHO E MUNDO DA VIDA: A RACIONALIDADE CAPITALISTA PRESENTE NA TÉCNICA, CIÊNCIA E TECNOLOGIA
}

\section{LABOR AND WORLD OF LIFE: THE CAPITALIST RATIONALITY PRESENTS IN THE TECHNIQUE, SCIENCE AND TECHNOLOGY}

\author{
Silvia Maria de Araújo ${ }^{1}$; Daniel Lopes Cinalli ${ }^{2}$ \\ ${ }^{1}$ Universidade Federal do Paraná - UFPR - Curitiba - Brasil - saraujo@swi.com.br \\ ${ }^{2}$ Universidade Federal do Paraná - UFPR - Curitiba - Brasil - danielc@,sofhar.com.br
}

Recebido para publicação em: 28/09/05

Aceito para publicação em: 20/11/05

\begin{abstract}
Resumo
A racionalidade capitalista-instrumental que invade o mundo da vida é aqui discutida sob o prisma do trabalho. A subjetividade comprometida do trabalhador nesse processo é um dos seus maiores efeitos das transformações técnicas, tecnológicas e cientificas ocorridas no século XX e postas à disposição da acumulação capitalista, sobretudo a partir da adoção das formas flexíveis e enxutas de organizar a produção e o trabalho. A moderna indústria automobilística instalada na Região Metropolitana de Curitiba, desde meados dos anos 1990, é um desses exemplos de transição. As intensas transformações sociais que ocorreram nas últimas três décadas no mundo do trabalho foram provocadas por uma avalanche de inovações na organização da produção e do trabalho. Os efeitos das mudanças em curso se expandem para diferentes âmbitos da sociedade e se impõem para a sobrevivência e inserção de grupos sociais emergentes na vida econômica, cada vez mais integrada. A construção do texto resgata as idéias de Weber sobre um processo racionalinstrumental que ganha corpo na modernidade, apresentando a proposta e Habermas sobre a ação comunicativa como alternativa às conseqüências dessa lógica hegemônica e devastadora do ser social. Ao analisar a invasão do mundo sistêmico sobre o mundo da vida e a continuidade desse processo, o artigo reflete a relação racional/subjetivo, colocando a indagação: nas condições produtivas das indústrias de caráter transnacional, que integram o complexo automotivo no Paraná, está-se diante de uma racionalidade ou irracionalidade capitalista, quando o olhar se detém no trabalhador? Crítica teórica e entrevistas com trabalhadores dão suporte às respostas aqui ensaiadas.
\end{abstract}

Palavras-chave: Trabalho; racionalidade; mundo da vida; subjetividade; tecnologia.

\section{Introdução}

Visualizar a reestruturação produtiva imposta à indústria automotiva tradicional para se adaptar às novas exigências do capital equivale a acompanhar o deslocamento das contradições que se acumulam na, hoje pouco significativa, clássica divisão das atividades em setores primário, secundário e terciário. O capital financeiro em auto-expansão e a reestruturação produtiva migraram para países como o Brasil e aqui provocaram o processo de desconcentração da indústria automobilística, na última década. Tem-se a geração de um novo tipo de produtividade, capaz de 
conectar diversos setores, na competição que é própria da natureza capitalista das ações, mas a ser despertada em cada área e conjunto de atividades, ao estabelecer elos que, para atender a dimensão econômica, inovam em tecnologia e organização do trabalho. Desse modo, as montadoras que aportaram em fins da década de 1990, no Paraná, como a Renault e a Volkswagen-Audi, chegaram reestruturadas, com plantas maduras e layout apropriado para desenvolver a trilogia alta produtividade, maior competitividade e lucratividade.

$\mathrm{O}$ aparato das montadoras e seus sistemistas traz modificações também para os trabalhadores. Saber se a vida cotidiana corre sobre uma base racional ou irracional é a discussão posta neste artigo sobre as relações entre o mundo da vida e o sistêmico. Busca-se refletir sobre o que seria racional ou ato de irracionalidade no comportamento das organizações e seus efeitos nos sujeitos do trabalho.

A discussão se inicia com um resgate das idéias de Weber (2002) sobre racionalidade e sua explicação acerca da existência de um processo racional instrumental que comanda a vida moderna. A seção seguinte faz uma crítica ao racionalismo instrumental weberiano. São apresentados o paradigma da razão comunicativa proposto por Habermas (1988) e a conscientização do indivíduo pelo processo de subjetivação, apresentado por Touraine (1994), como possíveis reversões ao avanço do mundo sistêmico sobre o mundo da vida. O foco, antes sobre o processo histórico de racionalização econômica e administrativa, é apontado para alternativas que emergem devido os efeitos dessa lógica capitalista sobre a vida e o trabalho. Na última seção, apresenta-se a interrelação entre os mundos do sistema, da vida e do trabalho. Os mundos da vida e do trabalho são ameaçados pelo avanço capitalista que despersonaliza e "coisifica" as relações sociais.

Parte-se da ligação estabelecida entre ciência e técnica, sobreposta no século XX pela relação entre ciência e tecnologia que, liderada pelos interesses do capital, transforma os mundos do trabalho e da vida. Esses são vividos e percebidos como separados, repletos de relações sociais complexas, marcadas por um sistema mecânico de impessoalidade e "coisificados", como atestam os depoimentos de trabalhadores da indústria automotiva, neste início do século XXI.

\section{Racionalidade e trabalho no pensamento contemporâneo}

Gerth e Mills (1968) mantêm um ponto de vista sobre a racionalidade que opõe as idéias de Marx e Weber, possibilitando introduzir o assunto. A argumentação prende-se à idéia de que, para Marx, a economia moderna é irracional, enquanto para Weber, além do capitalismo moderno não ser irracional, as suas instituições seriam "a materialização mesma da racionalidade" (Idem, p. 66). Ocorre uma focalização de abordagens diferentes entre os dois autores clássicos. Uma vez que Marx se preocupa com os efeitos de uma racionalização que se mostra irracional sobre a sociedade, Weber demonstra um processo racional instrumental que comanda a vida moderna.

$\mathrm{O}$ que os autores apontam como irracionalidade em Marx deve ser visto em outra perspectiva. O capitalismo seria irracional por se tratar de uma contradição entre as forças produtivas e as relações de produção com efeitos sobre a sociedade. As conseqüências de um progresso técnico racional avesso ao desenvolvimento da vida humana seriam provas de que não se trata de uma racionalidade, mas de uma irracionalidade ao não considerar os efeitos sobre o mundo vivido e seus produtores, os homens. Há em Marx (2002) a consciência de que o capitalismo se move e continua a mover-se por interesses dos proprietários dos meios materiais de produção. A sua crítica, contudo, atinge o resultado desta racionalidade.

Racionalidade é um atributo variável da ação humana. Diz respeito a algum objetivo, interesse ou valor perseguido pelo sujeito em condições de: levar em conta o exame das alternativas possíveis na situação; individualizar as variáveis externas que possam influenciar os resultados da ação, calculando a alternativa mais provável; avaliar com método as conseqüências das diversas alternativas; ponderar de modo comparativo a utilidade e o valor de qualquer conseqüência; otimizar a utilidade e o valor máximo, não importa se econômico, afetivo, político ou outro e fazer disso, objeto de critérios de decisão; encarar a ação como algo efetivo e conscientemente empreendido. (GALLINO, 1993, p. 531-532). Entender como ela se constitui é pré-requisito para a 
discussão de seus efeitos sobre a sociedade e o mundo da vida, plenos de significados elaborados na convivência.

As diversas formas de organizações sociais são a expressão de como, na sociedade contemporânea, a racionalidade se torna um valor ou uma norma, capaz de conformar indivíduos e grupos, moldando classes sociais, aprisionando-as com seu poder ideológico. A racionalidade do agir econômico é uma formação histórica que se identifica com o desenvolvimento do capitalismo. A concepção de racionalidade técnica diz respeito à lógica racional orientada pelos procedimentos técnicos. A técnica responde a uma necessidade, demanda ou exigência histórica de um grupo ou de segmentos de uma estrutura social. Embutidas na concepção de técnica estão as noções de invenção, inovação e progresso técnico próprias de cada cultura, no caso, a capitalista. Do ponto de vista sociológico, a invenção de uma técnica é menos relevante que a sua adoção e difusão em uma coletividade, a inovação.

A racionalidade apresenta-se, no plano do conhecimento, como o fenômeno da ciência que desmitificou o mundo. Ela substituiu a revelação e muitas explicações de caráter mítico por explicações racionais ou científicas. Pode-se dizer que foi esse ethos da sociedade tecnológica em nascimento que levou Weber a opor a racionalidade ao tradicionalismo. A ânsia pelo lucro e o ganho material-financeiro existiram em outras épocas e não constituem características próprias do capitalismo no ocidente. Mercadores árabes, comerciantes indianos e chineses também exerciam suas atividades objetivando o lucro e, no entanto, esse comportamento não é identificado como "ação racional capitalística". O capitalismo se diferencia das atividades "pré-capitalistas" pela conduta racional, a organização do trabalho, a persecução do dinheiro, ao invés da aventura. Para Weber (2002, p. 26), o capitalismo identifica-se com a busca do lucro sempre renovado por meio da empresa permanente, capitalista e racional. A constituição da empresa e sua diligência com o capital tornou-se o diferencial no sistema ocidental moderno, que tomou as atividades econômicas como inofensivas à esfera social.

A racionalidade funda-se na convicção de que as coisas encontram a sua explicação nelas próprias e não no exterior, no mito ou na tradição. Decorre daí, o fenômeno do trabalho com ênfase na racionalidade técnica. $\mathrm{O}$ trabalho explica-se por si, pelo mundo que cria em função da atividade produtiva. No plano da ação prática, a racionalidade implica a investigação constante dos meios mais objetivamente eficazes com vistas a fins definidos como realizáveis. Nesse processo, não se apresenta o trabalho como uma atividade prática por excelência, a ação criativa capaz de produzir valor? As finalidades e os meios que justificam a racionalidade técnica não são encarados como adquiridos, mas estão sujeitos a constantes revisões que recolocam a questão. Essa atitude mental esteve na origem da revolução industrial e do progresso técnico e científico, persistindo no capitalismo atual. Na teoria weberiana, como ações econômicas e administrativas racionais com relação a fins, a organização em termos capitalistas da produção, a instauração de uma administração organizada em termos burocráticos foi a seqüência natural para o desenvolvimento do capitalismo.

A burocracia, mais propensa às ações do Estado, é adotada também pelas empresas com a missão de colocar em prática uma organização baseada em especializações de funções administrativas, harmonizadas com finalidades objetivas (WEBER, 1968). Ao se tomar o processo de burocratização como conseqüência de um desenvolvimento da racionalização, um aparato de adequação dos meios para alcançar os fins estipulados pela organização empresarial, percebe-se em sua estrutura a predominância de uma lógica que coíbe governos pessoais por uma atitude racional e solidária aos interesses da empresa. Arendt (2003, p. 55) define a burocracia como a "substituição do governo pessoal pela burocracia que é o governo de ninguém"; leia-se, impessoalidade, como se a administração e o trabalho fluíssem por processos racionais próprios, dos quais se valem os interesses econômicos da empresa e que podem se livrar dos vínculos pessoais, empecilhos aos empenhos capitalistas.

Para Weber, o progresso da racionalidade sobre nosso mundo é indissociável do desenvolvimento das organizações, da burocracia, do Estado, do capitalismo em essência. Elementos que comprovam o aspecto racional interiorizado no mundo ocidental e que se mantêm 
até os tempos contemporâneos são identificados por Carvalho (1998, p. 2) como "o surgimento do cálculo racional dos custos da produção, a institucionalização do trabalho assalariado, o aparecimento de uma nova maneira de pensar e de agir que favorecia o processo de acumulação, a contínua incorporação da ciência e da técnica ao processo produtivo, a modificação do Estado”.

Os estudos sociológicos têm dado pouca atenção à técnica em geral, concentrando-se sobre a tecnologia moderna, entendida como a aplicação da ciência à técnica de produção e organização industrial e de projeto de produtos, cuja expressão pode ser ilustrada pela automação. Quando a técnica é aplicada instrumentalmente na busca de um melhor resultado como volume, qualidade, quantidade, economia de tempo e recursos ou, mesmo, de um resultado, algumas vezes irrealizável, diz-se da obtenção de um progresso técnico. O capitalismo, por exemplo, como uma ação racional, para poder se firmar teve necessidade da adoção generalizada de técnicas de mensuração do tempo, de técnicas do direito e da administração. (GALLINO,1993, p. 686-690)

Este texto analisa os efeitos dessa racionalização sobre o mundo da vida. Cabe mencionar alguns deles. A utilização do conhecimento científico e técnico, sobretudo no processo administrativo e produtivo, foi incentivada por considerações econômicas da empresa. Esse ambiente estimulou o fortalecimento da esfera racional, técnica e científica e, nesse contexto, as relações pessoais, culturais e de trabalho não sobrevivem sem sofrer alguma alteração. A divisão do trabalho adequada aos interesses capitalistas, aliada ao aparato técnico-científico, forma um complexo de relações que fere a liberdade do ser humano (CARVALHO, 1998; HABERMAS, 1988; WEBER, 2002). A padronização de rotinas e procedimentos produtivos ou administrativos transforma o indivíduo em uma engrenagem ou mero ocupante de um cargo, ao invés de um ser dotado de criatividade, sentimento e vontade. Quando questionado sobre a necessidade de fazer algum planejamento prévio de suas atividades diárias, um montador da indústria automotiva relata: "Não, é dispensável. Porque você já sabe todo dia o que vai ser feito, qual a meta, qual a produção. A gente lá é tipo um robozinho. Faz sempre a mesma coisa".(PAIXÃO, 2003, Entrevista ${ }^{\circ} 1$ com Trabalhador da Indústria, ago. 2004).

Paradoxal nesse comportamento é serem essas as competências cobradas do trabalhador, na atualidade, reduzindo-o a um simples fator de produção. Daí, a expressão "recursos humanos", criticada por Gorz (2003, p. 71), como a imagem da empresa transformada em lugar de aperfeiçoamento pessoal para seus assalariados. Qualquer intenção que contradiga o percurso dessa racionalidade técnica instrumental adaptada à esfera administrativa é coibida com uma contra ameaça sobre o seu emprego e a permanência do trabalhador no mundo do trabalho. O jogo capitalista não deixa saída ao trabalhador remunerado de qualquer nível: adapta-se, subordinando-se às regras dessa forma de produzir, intensificada com a mudança para o paradigma produtivo da acumulação flexível (HARVEY, 2002).

A possibilidade de exclusão do mercado de trabalho passa a ser uma nova forma de servidão que aprisiona o homem à sobrevivência e de seus dependentes, gerando apreensão e sofrimento tanto quanto para aqueles que, empregados, temem a competição e a demissão (DEJOURS, 2003). A modernização das técnicas de organização do tempo, trabalho, produção e administração é resultado de um desenvolvimento racional capitalista que imita a modernização reflexiva, como efeitos dessa racionalização no mundo da vida e da sociedade.

A impessoalidade nas relações de trabalho "produz profissionais deploráveis, carentes de heroísmo, espontaneidade humana e inventividade", na opinião de Gerth e Mills (1968, p.68), porque reduz a participação do trabalhador a simples fator de produção. A superficialidade do tratamento dado à força de trabalho pode ser demonstrada pelo depoimento de alguns trabalhadores da indústria automotiva, como na empresa $A$, seus nomes são substituídos por números: "Você é simplesmente um número. Pra você ter uma idéia, eu me lembro do meu número de chapa até hoje. (...) Quantos anos depois e eu sei de cor. Porque eles não me perguntavam teu nome: 'qual a tua chapa?"' (PAIXÃO, 2003, Entrevista $n^{\circ} 2$ com Trabalhador da Indústria, jan. 2004). Na empresa B todos os funcionários são chamados pelo nome, entretanto, sua qualificação, função e nível de experiência dentro da fábrica são indicados por bótons coloridos que classificam de uma maneira rápida e impessoal cada trabalhador: "Cada função tem um bóton, o monitor tem um bóton verde 
claro, os três ZP2 ${ }^{1}$ têm o verde escuro e o resto do pessoal, no caso os montadores, têm bóton amarelo, que é aprendizado. Quem entrou hoje tem bóton vermelho".(Idem, Entrevista $n^{\circ} 3$ com Monitor da Indústria, set. 2004).

O medo do desemprego e das dificuldades financeiras decorrentes servem de suporte para essa racionalidade capturar não apenas a força de trabalho fiel a um salário, mas também para aprisionar a consciência do indivíduo e esfumar seu processo de subjetivação. Esse ambiente favorece a alienação que, por um de seus aspectos, cria o desencontro do ser humano com seu trabalho - são aspectos da alienação do homem: alheamento do produto do trabalho, dos outros indivíduos (alienação do ser), da natureza na qual vive e da sua natureza interna. Pelo receio de ficar desempregado e necessidade do salário para a manutenção de sua vida, o trabalhador se (a)sujeita às regras do jogo capitalista racional, como revela um entrevistado: "No começo [do trabalho na fábrica] foi aquela novidade, depois passou pra uma satisfação, e agora passou para uma saturação. Os caras não suportam mais trabalhar, os caras vão porque tem que ir, porque sabem que não vão conseguir um salário que eles ganham lá, aí fora." (PAIXÃO, 2003. Entrevista $\mathrm{n}^{\circ} 2$ com Trabalhador da Indústria, jan. 2004).

A racionalidade que se alastra pelos diferentes redutos da vida causou dúvidas sobre seus benefícios ao próprio Weber. Em A ética protestante e o espírito capitalista, tece uma digressão sobre a questão da felicidade pessoal, que ainda hoje perturba estudiosos:

\begin{abstract}
“... parece por demais irracional esse tipo de vida que o homem existe para seu negócio, quando deveria ser ao contrário" (p. 61). "Antes a forma de organização era capitalista; as atividades do empreendedor tinham um caráter puramente comercial; o uso do capital investido, o negócio era indispensável, e, finalmente, o aspecto objetivo do processo econômico, a contabilidade, era racional. Mas se consideramos o espírito que animava o empresário, tratava-se de um negócio tradicionalista: tradicional o modo de vida, tradicional a margem de lucro, tradicional a quantidade de trabalho, tradicional o modo de regular as relações com o trabalho." (WEBER, 2002, p. 58).
\end{abstract}

Para Habermas (1975, p. 313), o período onde as tradições culturais, administrativas e produtivas reinavam era mais equilibrado que o momento onde a razão instrumental e econômica predomina: "o esquema estável de um modo de produção pré-capitalista, de uma técnica préindustrial e de uma ciência pré-moderna (...) apesar de progressos consideráveis, nunca atingiram aquele grau de propagação a partir do qual sua racionalidade se torna uma ameaça aberta à autoridade das tradições culturais". A razão "secularizou" e "desenfeitiçou" as imagens do mundo, para Habermas (1975), ao romper com um comportamento produtivo-administrativo-cultural enraizado no tradicionalismo e substituir atitudes racionais com relação a valores por um comportamento em relação a fins.

Ao mesmo tempo que esse comportamento racional se libera dos mitos e das tradições, embrutece a biografia dos homens, livrando-a da espontaneidade e criatividade. Ao contrário, incentiva-os à participação no jogo capitalista por meio de ideologias e formas coercitivas, submetendo-os a uma sociedade de excedentes que valoriza o capital antes da vida, ou melhor, onde valoriza a vida somente como criadora de valor e, por decorrência, de capital. Frente à dura sobriedade experimentada pelos trabalhadores em tempos de racionalidade, transparecem aqui os primeiros questionamentos sobre uma irracionalidade travestida de racionalidade que se sustenta ainda hoje.

\title{
3. Na busca do consenso comunicativo, uma crítica à racionalidade instrumental
}

Embora tenha compreendido a racionalidade que se alastrou e se fixou no mundo, a teoria weberiana sofreu críticas de diversos pensadores. É inegável o terreno desbravado por seus estudos, que resultou em ponto de partida para o desenvolvimento de novas teorias e paradigmas. Reis (1999) assinala na teoria de Weber uma unilateralidade instrumental, um excesso de atenção aos

\footnotetext{
${ }^{1}$ ZP2 é o cargo de multiplicador de tarefas.
} 
aspectos econômicos e políticos do capitalismo, que termina por negligenciar os aspectos sociais e humanos desse processo racionalista.

Habermas (1988), por outro lado, discute a sociedade pela visão de duas razões: a instrumental e a comunicativa. Com esta última propõe um novo paradigma que parte de uma crítica à razão instrumental weberiana e diverge para uma racionalidade pautada na comunicação, eivada de aspectos prático-morais, expressivos e subjetivos, em busca do consenso intersubjetivo.

Touraine (1994) compartilha uma visão bipolar da modernidade: racionalização e subjetivação, onde esta seria responsável por transformar o indivíduo em sujeito consciente, capaz de atuar no equilíbrio entre a racionalidade instrumental e o mundo vivido pelos homens. De uma maneira geral, a razão é criticada por ser expressão de poder na forma de conhecimento e ser produtora de dominação, contrastando diferentes posições, na medida em que tanto para Horkheimer quanto para Adorno, a razão constitui uma fonte de dominação, principalmente dos homens entre si. A razão, para eles, é sinônimo de reificação, de exercício de poder e de barbárie. A idéia de que a razão é uma possibilidade libertadora e emancipatória não passa de uma mera ilusão iluminista, pois "Adorno aniquila a razão, quando a põe a serviço exclusivo da dominação.(...) as teorias são concebidas como ideologia, contaminadas e imbuídas de relações de poder". (MEDEIROS, 2003, p. 9).

A racionalização é travestida de uma forma de dominação política, como "exercício do controle", para Habermas (1975, p. 304). Portanto, razão e poder se equiparam. A dominação passa a ser legitimada pelo capitalismo e suas relações de produção, sendo a "oportunidade de ter um comando obedecido por um grupo dado de pessoas", na visão weberiana, enquanto "poder é a oportunidade existente em uma relação social que permite a um sobrepor sua vontade sobre o outro mesmo contra resistência" ( WEBER, 1978, p.117). O comportamento do mercado econômico, com sua sede pelo lucro, as forças ideológicas e suas inverdades, a ciência com seus instrumentos para o controle da natureza e do próprio homem, trazem à ordem do dia a utilização maquiada do poder e dominação pela racionalidade. De maneira geral, a razão é criticada por conter poder e ser fonte de dominação. Esses fenômenos são decorrência do ajuste ou reciprocidade nas relações sociais com o desenvolvimento capitalista desigual. A diferença é de grau na relação.

Para Habermas (1975), a sociedade consiste em mundos complementares: o sistêmico e o mundo vivido. Este último é a dimensão das sensações, das maneiras, dos sentimentos, da comunicação, dos acontecimentos, da cultura e do entendimento entre os sujeitos. O mundo da vida é o ambiente cotidiano onde os indivíduos agem e se defrontam com suas ações e reações, relações sociais, interpessoais e subjetivas. Já, o mundo sistêmico é a esfera do trabalho e do mercado orientado pela ação estratégica-instrumental capitalista. As fronteiras entre eles não são bem definidas como sugere a teoria, há uma interação entre elas. Se por um lado, o mundo da vida tenta integra os indivíduos de modo social, consensual, comunicativo e intersubjetivo, por outro, o mundo do sistema confere uma integração sistêmica regulada pelo mercado e pela racionalidade econômica.

Gorz (2003) indica que "Habermas insiste sobre o fato de que a sociedade deve ser entendida como algo que diz respeito, ao mesmo tempo, ao 'sistema' e ao 'mundo da vida', isto é, integrada social e funcionalmente, sem jamais poder ser inteiramente nem uma, nem outra coisa". Ocorre, assim, uma permeabilidade entre os mundos e não uma separação estrita. Embutidos a um único mundo físico, mundo da vida e sistema refletem esse jogo sobre a biografia de seus integrantes, os seres humanos. Estes verificam em seu dia-dia a interferência de forças sistêmicas sobre ps seus sentimentos. Por exemplo, quando uma nova meta de produção faz aumentar o ritmo de trabalho compromete não apenas a qualidade do produto, pois o trabalhador é cobrado por isso, como compromete suas condições físicas e mentais decorrentes do aumento do ritmo na produção. De acordo com depoimento de trabalhador da indústria automobilística, é possível comprovar que o aumento da velocidade de trabalho orientado pela estratégia sistêmica, transmite reações em seu mundo da vida: cansaço, sobrecarga, exigência demasiada, alteração de humor e, muitas vezes, sentimentos confusos: 
Baixou [a produção] para 400 carros por dia, com um número " $x$ " de pessoas. Aí, aumentou para 440, com o mesmo número de pessoas. Aumentou para 460, com o mesmo número de pessoas; aumentou para 480, com o mesmo número de pessoas; aumentou para 500 , com o mesmo número de pessoas. Quer dizer, eles iam dosando e vendo: Ó, o pessoal está agüentando, o pessoal está fazendo [sic]. Manda embora, manda fazer. Não vamos chamar mais gente. O pessoal está dando conta, continua fazendo. (...) Stress me aborrece, me deixa nervoso, me deixa bravo, enfim, irritado. (...) E outra coisa assim que te deixa pra baixo, que te deixa down, é quando o chefe faz você ver, faz você sentir que não é ninguém ali dentro. Isso já aconteceu comigo e é ruim, você desanima. Você pensa em sair, você pensa em relaxar no serviço, você pensa em se afastar. (...) E diante dessas situações que eu tive, situações constrangedoras, situações humilhantes, situações assim que me deixaram mal, me estressou, me deixou aborrecido e me criou um descontentamento. (CIMBALISTA, 2005. Entrevista $n^{0} 4$ com Trabalhador da Indústria, jun. 2005).

Ocorre a sujeição do trabalhador à objetividade racional da vida social moderna exposta e perseguidora de interesses materiais e materialistas. Feenberg (2004b) argumenta que Habermas desmitifica a ação racional em relação a fins quando subtrai dela seu real objetivo de controlar e "tecnicizar" o mundo da vida. Este, por sua vez, sendo considerado o ambiente cotidiano onde os indivíduos agem e se defrontam com suas ações, relações sociais, interpessoais e subjetivas, é passível dessa influência racional. Os homens deixam de preservar o mundo da vida.

Para precisar a influência do progresso técnico e científico no quadro institucional em vias de modernização, Habermas (1975) propõe categorias de análise diferentes das de Weber e Parsons, procurando determinar o significado da racionalidade técnica e científica, como expressão de uma forma de vida específica - a "totalidade histórica" do mundo da vida. A ciência, a técnica, a razão instrumental, a burocratização e o trabalho organizado de forma racional são exemplos de uma tentativa de colonização e "tecnicização" do mundo vivido, uma tentativa de adaptá-lo ao mundo sistêmico. Os efeitos sobre a sociedade e o homem não podem ser desprezados. Nessa linha, Habermas se refere a uma racionalização comunicativa que pode restabelecer a harmonia do homem consigo e com o mundo, uma troca entre a relação sujeito-objeto pela linguagem-mundo.

A razão comunicativa é a proposta de um paradigma centrado na argumentação e contraargumentação dos indivíduos, na linguagem, na fala, no consenso e na intersubjetividade posta na relação sujeito-sujeito. É uma razão que caminha à margem da condição instrumental e se baseia no entendimento mútuo de ouvintes sobre o mundo objetivo, social e subjetivo. É uma espécie de compartilhar socializado e institucionalizado, ainda que o autor coloque o consenso como condição. Com a ação no plano da comunicação intersubjetiva, ocorre uma mudança de perspectiva: os participantes dessa ação tendem a orientar um enfoque de compreensão dos sujeitos em interação. "O agir comunicativo distingue-se, pois, do estratégico, uma vez que a coordenação bem sucedida da ação não está apoiada na racionalidade teleológica dos planos individuais de ação, mas na força racionalmente motivadora de atos de entendimento, portanto, numa racionalidade que se manifesta nas condições requeridas para um acordo obtido comunicativamente" (HABERMAS, 1990, p. 72).

Em um certo sentido, a tese habermasiana recupera a subjetividade do indivíduo negada pelo processo unilateral racional e pelo determinismo econômico-administrativo, expresso de forma dominante no determinismo tecnológico que secundariza a lógica social, o humano, desumanizando-o (ARAÚJO et al., 1998). Na tradição mais recente da escola de Frankfurt, Habermas concebe a teoria como crítica em relação ao presente, capaz de vislumbrar perspectivas. Ao analisar o papel da ciência e da técnica no capitalismo tardio, demonstra os interesses subjacentes aos projetos científicos e técnicos da sociedade moderna e percebe o progresso técnicocientífico como ideologia legitimadora da dominação capitalista. Critica o pensamento positivista de valorização da técnica, pois a sua preocupação é de esse potencial tecnológico em contínuo desenvolvimento, por princípio, não produz, necessariamente, a emancipação humana.

A racionalização institucionalizada da ciência e da técnica constitui o fundamento da legitimação da dominação econômica e política, na medida em que a submissão dos homens a um aparato técnico e científico é apresentada como necessária à promoção do bem-estar da população, apesar de perpetuadora de um modo de produção que restringe a liberdade dos próprios homens. 
Por isso, Habermas opõe-se ao pensamento pessimista de Weber quanto ao processo de racionalização, para quem esse teria acarretado uma perda de sentido na racionalização cultural, em conseqüência do desencantamento das visões tradicionais do mundo e uma perda de liberdade na racionalização social, em função da burocratização do Estado e da economia, segundo Rouanet (1987).

A proposta de Habermas (1990) é uma tentativa de responder à interpretação weberiana da racionalidade sem saída, que legou uma visão técnica-instrumental integrada à ordem dominante. A economia capitalista tende a dirigir a sociedade para uma existência menos socializada, destruidora da intersubjetividade. A sugestão de uma racionalidade plantada na comunicação lança luz para combater a tendência à contração do mundo da vida e resgatar o social compartilhado. A sobreposição do mundo da vida pelo sistêmico gera conseqüências sobre a sociedade e o ser humano que não podem ser desprezadas. Em verdade, essa sobreposição é um descontrole, um desequilíbrio que expõe a separação forçada dos dois mundos nas condições de trabalho e vida, como prova o relato:

\begin{abstract}
... os efeitos que a gente tem é que, às vezes pelo volume de trabalho (...) no final do dia, umas 15,16 horas, quando a gente vê que não vai dar conta do trabalho e a gente vai ter que ficar até umas 19 horas, a gente começa a ficar meio tonto, meio zonzo, meio frustrado, dá uma palpitação no coração... Você não vai conseguir cumprir com o volume e você não quer ficar mais depois do trabalho. Você quer ir pra casa, você quer fazer tua vida pessoal, então, dá esse desespero, de certa forma dá uma frustração (CINALLI, 2003. Entrevista $n^{\circ}$ 5 com Analista de Logística, fev. 2005).
\end{abstract}

A sujeição dos homens a um modelo de vida conduzido pela racionalidade capitalista desbota pouco a pouco o mundo dos sujeitos e abre espaço para a crítica desse processo, assim como a tentativa de sua superação. Nessa linha, Habermas (1988) é um dos estudiosos que apontam uma alternativa. A razão comunicativa poderia restabelecer a harmonia do ser humano consigo mesmo e com o mundo, possibilitando uma troca entre a relação sujeito-objeto pela linguagemmundo. É a proposta de um novo paradigma centrado na argumentação e contra-argumentação dos indivíduos, na linguagem, na fala, no consenso e na intersubjetividade (relação sujeito-sujeito). É uma razão que caminha à margem da condição instrumental e se baseia no entendimento mútuo de ouvintes sobre o mundo objetivo, social e subjetivo. A visão habermasiana da razão comunicativa assenta-se sobre a idéia de que ela é emancipadora, enquanto que a razão não-comunicativa "é feita para subjugar, controlar e dominar", para Bastos (1998b, p. 59), visto que são orientadas sobre uma base de coerção, de poder, de dominação e de desacordo.

O paradigma da razão comunicativa não somente contesta a razão instrumental, mas perfaz uma crítica ao pensamento de Marx. Giddens (1998) indica que a teoria hegeliana do trabalho e interação é a raiz da crítica habermasiana ao pensamento marxiniano. Para Hegel, "trabalho e interação eram dois aspectos chaves do processo de auto-formação dos seres humanos em sociedade ou do desenvolvimento da cultura humana. (...) irredutíveis entre si" (Apud GIDDENS, 1998, p. 298). Foi esse o vértice do desacordo teórico entre Marx e Habermas que abriu caminho à razão comunicativa. A irredutibilidade entre trabalho e interação é uma das prerrogativas para o fortalecimento das estruturas comunicativas no contexto social.

Marx criou sua teoria sobre a dialética das relações de produção versus as forças produtivas. As primeiras foram vistas por Habermas como a cristalização própria da noção de interação. Entretanto, ao tratar do trabalho frente o conflito das relações sociais de produção e das forças produtivas capitalistas, Marx (1977) teria apostado nessa dialética como a questão central da sociedade, onde o determinismo econômico e as condições materiais sobre-determinariam a vida social e a consciência do ser humano. Pela visão de Habermas, esse pensamento de Marx caracteriza um problema epistemológico, segundo Giddens (1998), pois teria reduzido trabalho e interação entre si. O papel da comunicação dentro da estrutura interativa teria se enfraquecido em função da valorização intensa da razão instrumental. A razão comunicativa representaria, então, 
mais que um resgate da estrutura comunicativa à problematização dos contextos sociais modernos, pois seria uma correção epistemológica à irredutibilidade entre trabalho e interação.

Touraine (1994) aponta uma saída ao paradigma habermasiano da ação comunicativa: a interdependência entre razão e subjetivação. A partir do século XVIII, a modernidade proclamou a razão como linha de pensamento da sociedade. Marcou o fim da sociedade baseada nas tradições, nos costumes, nos mitos e nas crenças. A valorização da razão conduziu o desenvolvimento do capitalismo por meio da modernização dos instrumentos de produção, das técnicas de organização administrativa e do avanço científico-tecnológico. A modernidade não criou apenas a sociedade da razão, mas a sociedade do sujeito. A industrialização e a ciência se fortaleceram na razão que vinha do homem, quando a atitude racional com relação a fins abandonou as formas tradicionalistas de pensamento e se prendeu à figura do homem consciente, que pensa. Abriu-se espaço para a transformação do indivíduo em sujeito e este em ator social, que encarna o papel de mudar o mundo. Essa dualidade interativa razão-sujeito marcou o início da modernidade, porém não se sustentou ao longo dos séculos.

O ser humano foi sujeito e ator social quando "desenfeitiçou" as imagens do mundo e trouxe a razão para modernizar sua estrutura capitalista. Entretanto, o desenvolvimento da racionalidade instrumental como lógica de funcionamento do capitalismo desconstruiu o sujeito ao retirar-lhe sua liberdade, vontade, criatividade e consciência. Quebrou-se a bipolaridade razãosujeito/ciência-consciência. A razão instrumental deixou de ser dirigida pelo homem e passou a governá-lo, a controlar o seu mundo. Touraine (1994) promove o reaparecimento do sujeito por meio da subjetivação, como forma de defesa das ameaças racionais técnicas e instrumentais que fragilizam o mundo da vida.

Habermas (1988) também percebe esse processo de ameaça à intersubjetividade. Para ele, existe a necessidade de libertação nas relações de produção, de resgate da subjetividade individual que combata o racionalismo instrumental e seja co-participante de uma vitória do mundo da vida sobre o sistêmico. Essa necessidade se expressa como o "aguilhoamento à intersubjetividade dos trabalhadores socializados na grande indústria, intersubjetividade paralisada agora pelo automovimento do capital, para que a vanguarda mova o trabalho vivo, o trabalho criticamente vivificado, contra o trabalho morto e conduza ao triunfo do mundo da vida sobre o sistema da força de trabalho desumanizado" (Idem, p. 481).

A concepção de racionalidade técnica diz respeito à lógica racional orientada pelos procedimentos técnicos. De qualquer modo, a técnica responde a uma necessidade, demanda ou exigência histórica de um grupo ou de segmentos de uma estrutura social. $O$ fio condutor do desenvolvimento cientifico-tecnológico é delineado pelo interesse capitalista, uma vez que "as ciências modernas servem ao progresso técnico, ao fomento de crescimento capitalista e à administração racional", para Habermas (1988, p. 465). Weber também afirma que a "utilização técnica do conhecimento científico, tão importante para as condições de vida da massa do povo, foi certamente incentivada pelas considerações econômicas" (2002, p. 31). O avanço científico e técnico está associado a uma racionalização em benefício capitalista, exclusiva do capital tal qual uma relação de única dimensão. Por exemplo, os laboratórios farmacêuticos priorizam suas pesquisas científicas em medicamentos que podem atingir o lucro no mercado consumidor, ao invés de enfatizar pesquisas sobre doenças. Ao desenvolvimento de técnicas para controle do trabalhador acopla-se a intensificação do trabalho por meio de máquinas modernas que favorecem a extração da mais-valia relativa, ${ }^{2}$ fazendo avançar a tecnologia e a ciência com efeitos destruidores.

Feenberg (2004b, p. 2) menciona Heidegger ao dizer que este enxerga a tecnologia moderna como um instrumento destrutivo, em termos de, com a "própria tecnologia (...), perdemos a visão sobre o que é sacrificado na mobilização do ser humano e recursos para objetivos que ainda permanecem obscuros." Interpretações como essas acusam a racionalidade de ser travestida de

\footnotetext{
${ }^{2}$ A mais-valia relativa é aquela "decorrente da contração do tempo de trabalho necessário e da correspondente alteração na relação quantitativa entre ambas as partes componentes da jornada de trabalho.” (MARX, 2002, p. 366). Assim, ao fixar-se o tempo da jornada de trabalho, o tempo de trabalho necessário reduz-se frente o crescimento do tempo de trabalho excedente.
} 
irracionalidade. Tem-se uma racionalidade sobre o mundo sistêmico e suas metas, ao mesmo tempo que se aplica uma irracionalidade sobre o mundo da vida e seus habitantes. Uma situação ocorrida na indústria $A$ exemplifica a lógica racional que prioriza a produção com redução de custos e o descaso para com os integrantes do mundo da vida. Segundo o entrevistado, o sindicato cedeu diante da ameaça da indústria e conseguiu impor seu contrato de trabalho diversificado:

\begin{abstract}
... no ano de 2002, a [indústria A] chegou com um projeto chamado 5000 por 5000 , e esse projeto previa a contratação de 5000 trabalhadores. A [indústria $A$ ] chegou para o sindicato (...) e disse: Ou vocês concordam com um novo contrato de trabalho, com uma jornada superior e salário inferior, ou nós vamos produzir esses 5000 empregos em outra parte do mundo, seja no Brasil, seja na África, ou no Leste europeu. (ARAÚJO, 2002. Entrevista n ${ }^{\circ}$ 6 com Dirigente Sindical, jul. 2004).
\end{abstract}

A racionalidade capitalista institucionalizou a ciência e a técnica na medida que vinculou o avanço tecnológico-capitalista ao bem-estar da população. Perseguir uma alta produtividade e um eficaz domínio da natureza trazem promessas de recompensas sociais: sustento garantido aos indivíduos, uma vida mais digna e confortável, menos situações de miséria e fome, um respeito ao meio ambiente entre outros desequilíbrios sociais. Em A nova intransparência: a crise do Estado de bem-estar social e o esgotamento das energias utópicas, Habermas (1987) declara o fim das energias utópicas clássicas e analisa os tempos contemporâneos. À expectativa de uma vida digna, os homens chocaram-se com uma realidade bruta, oposta aos ideais utópicos. Desemprego, miséria, fome são exemplos de problemas antigos que estão potencializados no mundo de hoje. As "forças produtivas que se transformam em forças destrutivas" (Idem, p. 105) perdem sua inocência e produzem seus efeitos nos diferentes campos do mundo da vida e trabalho. Em verdade, o mundo da vida está se fragmentando frente à racionalidade a serviço do capital.

No pensamento que atribui ao próprio ser humano a incumbência de ser o sujeito das mudanças e da proteção do mundo da vida, Touraine (1994, p. 243) delineia a modernidade como "a criação permanente do mundo por um ser humano que desfruta de seu poder e da sua aptidão para criar informações e linguagens, ao mesmo tempo que se defende contra suas criações desde o momento em que elas se voltam contra ele". Tanto Habermas como Touraine tentam responder à racionalidade weberiana que a realidade histórica confirmou. Essa nos deixou uma visão técnicainstrumental integrada à ordem capitalista, que dirige a sociedade para uma existência cada vez mais desprovida da intersubjetividade. Seja pela sugestão de uma nova racionalidade eivada de comunicação ou por um equilíbrio trazido pela subjetivação do indivíduo são lançadas idéias que procuram combater a tendência à contração do mundo da vida pelo sistêmico e resgatar a integração homem e sociedade.

\title{
4. Ciência e tecnologia dominantes
}

A era da informação e do conhecimento marca a sociedade contemporânea e a conduz por um caminho onde ciência e tecnologia agem interativamente sobre uma diversidade de ambientes, como por exemplo, o mundo do trabalho. A tecnologia da informação que, para Castells (2000), se constitui em sistemas de informação, interage e ultrapassa o ambiente das empresas, responde, simultaneamente, por mudanças na estrutura dos setores econômicos tradicionais, nas forças competitivas e nas relações entre escala de produção e automação. O componente novo e cada vez mais persistente da flexibilidade entre os sistemas atinge, em conseqüência, os indivíduos e suas relações não apenas contratuais formais mas, também, subjetivas. A sua aplicabilidade impõe-se como um dos itens do desenvolvimento produtivo desde a segunda metade do século XX.

Para entender os efeitos causados pela combinação ciência e técnica é preciso compreender esse entrelaçamento, segundo Corrêa (1997). A ciência se constitui no conhecimento da realidade por meio de teorias, enquanto a técnica mede a relação homem e natureza, responsável pela transformação do real, pelo modo de fazer alguma coisa, pela produção de bens e serviços. São partes em interação. Utiliza-se de ciência para se criar tecnologia e esta influencia o andamento da 
ciência. A ciência produz tecnologia e, simultaneamente, é produzida pela técnica. Nesse jogo imbricado, a retroalimentação entre ciência e tecnologia cria um ambiente propício a benefícios recíprocos. Cabem questionamentos: quais são os seus efeitos sobre o mundo vivido? Em que medida o progresso tecno-científico e o crescimento econômico afetam o sistema social para alavancar condições de vida melhores e extensivas? Qual é a linha desses avanços?

Como o modo de produção capitalista requer uma ampliação contínua das forças produtivas, a introdução de novas tecnologias e estratégias é institucionalizada, ampliando-se a esfera dos subsistemas do agir racional com respeito a fins, rebaixando a supremacia tradicionalista do quadro institucional, na visão de Habermas (1975). Ao tecer a distinção entre "trabalho" e "interação", procura caracterizar as mudanças estruturais no quadro institucional da sociedade tradicional em transição para uma sociedade moderna. Sendo o trabalho, o agir racional com relação a fins (agir instrumental mais escolha racional) e a interação, o agir comunicativo mediatizado simbolicamente, resultam diferentes sistemas sociais conforme neles predomine uma ou outra forma de agir. A sociedade moderna aponta a possibilidade da ação racional com respeito a fins colocar em questão os fundamentos cosmológicos da legitimação da dominação.

Da conivência existente entre ciência e tecnologia em favor do capital surgem interferências na subjetividade. A interdependência entre pesquisa e técnica fez da ciência não somente uma força produtiva que transformou a razão do mundo, mas também numa arma de colonização do mundo da vida, argumenta Habermas (1975). Os padrões de ação instrumental não limitam sua atuação aos ambientes administrativos, produtivos e de serviços, mas operam em outros domínios sociais de caráter íntimo dos indivíduos, seja na padronização do desejo de consumir, na urbanização nos modos de viver, nas formas de comunicação, instituindo um estilo moderno de vida.

Muniz (1995) critica a maneira de produzir mercadorias e a relação homem-natureza como atividades alienadas e desprovidas de racionalidade. Alega que a ciência, a tecnologia e o capital aliados têm o poder de criar uma consciência alienada ou falsa, de tal modo que favorece a transmutação de um mundo de relações sociais complexas e pessoais para um sistema mecânico de relações impessoais adaptável ao capitalismo. Este mundo tem-se constituído com o apoio de uma racionalidade técnica que procura suprimir a consciência do sujeito, tornando-o volúvel à força das coisas, ao poder material sobre a subjetividade (ARAÚJO, 2003).

$\mathrm{O}$ modo de produção capitalista tem como fundamento de legitimação, num primeiro momento, a promessa de justiça, da equivalência das relações de troca. As novas formas de legitimações que se pretendem científicas, retirando da consciência pública, as relações de violência inerentes às trocas no sistema capitalista, constituem ideologias. Cria-se uma segunda natureza de relações e percepções que sobrepuja a histórica relação homem-natureza. Essa se resume a uma racionalidade que valoriza o conhecimento, a informação, a ciência e sua aplicação (a técnica) a serviço do capital, de modo que essa composição produz uma maquiagem ideológica à sociedade capitalista e de consumo, convencendo-a de ser esta uma formação societária natural, singular e benéfica para a maioria dos indivíduos. Hoje, as necessidades e objetivos humanos, o conhecimento científico, as formas de trabalho e o desenvolvimento das forças produtivas estão respaldadas pela forma e conteúdo encontrados nessa segunda natureza, afirma Muniz (1995). Assim, a integração social na segunda natureza é uma alienação dos sentidos, esfuma as intenções capitalistas e "nãosociais", encobre alternativas de uma sociedade justa, integrada ao espírito humano. O problema é que este sentimento de "pertencer" a essa sociedade subtrai dos indivíduos, a capacidade crítica de vislumbrar algo diferente, num processo que naturaliza uma situação historicamente construída.

A cientificização da técnica verificada ao final do século XIX indica que o progresso técnico e o progresso científico encontram-se em íntima circulação, inseridos no mesmo sistema. Habermas (1975) aponta o fato de o desenvolvimento do sistema social estar determinado pela lógica do progresso técnico-científico, ou seja, atribui-se a esse o caráter determinante da manutenção do crescimento econômico. Dessa forma, legitima-se a perda da possibilidade de manifestação da vontade democraticamente formada, substituída pelas decisões tomadas por equipes administrativas. $\mathrm{O}$ que se verifica é a substituição progressiva do agir comunicativo pelo agir racional com respeito a fins. A diferença entre uma e outra forma de ação já não é percebida. $\mathrm{O}$ 
trabalhador é dominado progressivamente por regras técnicas que promovem a sua adaptação a um mundo cada vez menos compreendido por determinações culturais específicas, em função da persistência de modelos científicos e técnicos.

A ciência e a tecnologia como suportes dessa segunda natureza não conseguiram manter seu véu ideológico e deixam transparecer suas conseqüências adversas à natureza, que inclui o homem em uma nova lógica crítica da vida, não mais dicotômica e separatista do raciocínio e percepção de inserção na sociedade (SANTOS, 1998). As "forças produtivas que se transformam em forças destrutivas", para Habermas (1987, p. 105) perdem sua inocência e produzem efeitos nos diferentes campos da vida. O trabalho amoldado a essa forma de sobrevivência material necessária foge, entre outros sintomas, de suas atribuições à subjetividade, ainda que o discurso enfatize, ad nauseam, o sujeito. Em verdade, o mundo da vida se encolhe frente a essa racionalidade a serviço do capital.

\section{O mundo da vida ameaçado}

Esta seção discute a interferência do mundo sistêmico sobre o mundo da vida, interpretando-a como uma ameaça, uma espécie de perda do aspecto humano no processo histórico de produção da vida não apenas material. A persistência no pensamento e na ação capitalista de uma racionalidade instrumental posta em tudo traz, como conseqüência, a invasão do ser humano em âmbitos de sua representação simbólica de "estar no mundo". O enfoque unilateral de ações cognitivo-instrumentais acaba produzindo uma reificação da prática cotidiana, ao dominar a consciência dos atores sociais. Como resultado, afasta dos indivíduos, o sentido de suas ações, além de mutilar compreensões culturais e sociais em função do clamor pelo pragmatismo, pela aplicação mecanicista do conhecimento, pela necessidade que se impõe de respostas imediatas nas ações.

Habermas identifica essa neutralização do mundo da vida com uma forma que vem sendo centralizada na vida social. A colonização ou "tecnicização" do mundo ameaça empobrecer a cultura com a alienação, a destruição de estruturas comunicativas, a mecanização das relações intersubjetivas. Há uma percepção de um antes e de um depois,

\footnotetext{
... não somente o encanto melancólico de algo passado para sempre, não somente o brilho de uma recordação nostálgica de algo que foi sacrificado à modernização sem compensação alguma, senão que, os processos de modernização são vistos seguidos, como por uma sombra, por um instinto (me atreveria a dizer) instruído pela razão, ou, em todo caso, pela sensação de que com a canalização unilateral e a destruição das possibilidades de expressão e comunicação, assim o espaço da vida privada como na esfera da vida pública, se desvanecem as oportunidades de voltar a reunir com naturalidade, em uma prática cotidiana pós convencional, aqueles momentos que outrora, nas formas tradicionais da vida, constituíram uma unidade. (HABERMAS, 1988, p. 468).
}

Além dos efeitos causados pelo acoplamento do caráter capitalista que penetra os poros do social, o mundo da primazia do capital revela os seus problemas ao realizar a reprodução material. Como exemplo tem-se a escassez de matérias primas renováveis na natureza, a competitividade acirrada de produtos, um mercado consumidor com baixo poder aquisitivo. $\mathrm{O}$ mundo sistêmico expõe a sua malícia no momento em que assenta a proposta de resolução de seus problemas sobre o mundo da vida. Há uma transferência de responsabilidade social para o indivíduo em projetos pessoais ou coletivos; há uma imputação de autoculpa num processo de individualização onde interesses e lucros se tornam sinônimos na sociedade capitalista.

Por comodidade, ausência de resistência ou uma voracidade que alimenta as ações racionais orientadas a fins, os desequilíbrios na esfera sistêmica são "resolvidos" com efeitos no mundo cotidiano dos homens. Resolvem-se os recursos naturais não renováveis explorando-se mais intensamente a natureza; combate-se a competitividade acirrada de produtos com mão-de-obra de baixo custo em outros países ou se utilizando máquinas e robôs, "soluções" de alta tecnologia. 
Ações como essas apenas transferem o problema para outros ambientes e não podem ser tomadas como racionais, pois trazem abalos estruturais à sociedade, à cultura e à personalidade dos indivíduos. Ao invés de uma solução conjunta de problemas, são utilizadas opções capazes de gerar mais vantagem competitiva ao mundo sistêmico. Há uma desconfiguração do mundo da vida para solucionar problemas criados pelo próprio sistema capitalista. São poucas as escolhas. Aos trabalhadores resta adaptarem-se a essa forma sutil de dominação. Diante das regras do jogo estipuladas pelo mundo sistêmico, pela força da ideologia dominante, pela alienação decorrente desse processo, pela fraqueza das políticas alternativas, permanece a subordinação ao sistema capitalista em suas diversas feições: trabalho atípico, temporário, precário, terceirizado, quando não, escravo e infantil.

Segundo Habermas (1987, p. 105), "as mesmas forças de incrementação do poder - das quais a modernidade extraiu outrora sua autoconsciência e suas expectativas utópicas - na verdade transformaram autonomia em dependência, emancipação em opressão, racionalidade em irracionalidade", sentidas na pele pelos integrantes do mundo da vida, como relata um entrevistado:

... eu não vejo que eu tenha muito futuro lá [na indústria automotiva] daqui há uns dois, três anos. (...) Eu quero me formar. Eu quero trabalhar mais um ano, pagar meu consórcio, comprar a minha casa. Quero me estabilizar financeiramente e, trabalhando lá, começar a entregar meus currículos pra uma coisa menos elétrica, pra poder aproveitar a minha vida, ter uma vida mais tranqüila com a minha esposa, ficar dez anos mais jovem [alusão a um trabalho menos intenso]. (CINALLI, 2003. Entrevista $n^{0} 5$ com Analista de Logística, fev. 2005).

No testemunho, percebe-se a opressão sobre os trabalhadores sua dependência vital e financeira do trabalho assalariado. A soma desses sentimentos resulta em um indivíduo-trabalhador comprimido até seu limite por um trabalho estafante que segue as ordens do mundo sistêmico. A sobrecarga e a polivalência de suas atividades pedem ao trabalhador uma cumplicidade de todos os seus sentidos. O emprego da "inteira individualidade humana" para exercer sua atividade é denominado homogeneização, por Heller (1972, p. 27). É a sobreposição da individualidade pelo trabalho e não uma integração entre eles. A racionalidade capitalista requer a absorção de todos os sentidos do homem para utilizá-los no processo de trabalho, precisa de todos focados e compenetrados no ato capitalista alienado de produzir. Essa homogeneização assume um sentido unilateral, quando não proporciona o retorno dessa relação à subjetividade do trabalhador, quando não há uma contrapartida. É, portanto, uma unificação do trabalhador pelas vias de poder da racionalidade capitalista. A homogeneização acontece como resultado da impossibilidade de luta frente o poder unificador do capital aplicado sobre as organizações produtivas.

Também se pode falar em uma homogeneização oferecida pela globalização como uma idéia-força persuasiva, um discurso que realiza a crença no neoliberalismo como um modelo único e inevitável (BOURDIEU, 1998). A flexibilização do trabalho e do trabalhador polivalente, a precarização das relações de trabalho e a deteriorização das leis de proteção ao trabalhador fazem essa homogeneização se chocar com as conquistas sociais do welfare state que não se efetivou no Brasil. A realidade dos trabalhadores europeus para trabalhadores é diferente daquela de países em que "o salário mínimo não existe, onde operários trabalham 12 horas por dia por um salário que varia entre $1 / 4$ e 1/15 do salário europeu, onde não há sindicatos, onde as crianças são postas para trabalhar (...) [há] o trabalho noturno, o trabalho nos fins-de-semana, as horas irregulares de trabalho, coisas inscritas desde toda a eternidade nos sonhos patronais", completa Bourdieu (1998, p. 49).

Aludindo o social organizado, Bourdieu pensa a dupla globalização-neoliberalismo como unificadora: por meio das ações e discursos, os países ricos forçam de cima para baixo a unificação à sua moda, dividindo a economia das realidades sociais pela utilização de políticas de redução de custos e flexibilização do trabalho para a ampliação da produção. A unilateralidade dessas ações extingue o que resta de solidário e humano no indivíduo, intensifica a exploração, aumenta a concentração de riqueza e alarga a desigualdade social, relegando o trabalhador. 
Em resumo, os problemas apresentados mostram que a razão firma um compromisso com o capitalismo que vai na contramão de uma racionalidade igualitária e criadora de consciência ou de um ambiente de entendimento mútuo e consensual. Em oposição às idéias habermasianas, o que se verifica é a substituição progressiva do agir comunicativo pelo agir racional com respeito a fins. $\mathrm{O}$ homem já não percebe a diferença entre uma e outra forma de ação, sendo dominado progressivamente por regras técnicas que promovem a sua adaptação a um mundo cada vez menos compreendido por determinações culturais específicas, em função da persistência de modelos instrumentais, científicos e técnicos.

É preciso discutir o contexto habermasiano no qual faz parte o trabalho. Se este pertence ao mundo do sistema ou ao mundo da vida, o trabalho é elemento construtor do processo de subjetivação, como propões Touraine (1994). O mundo do trabalho é composto pelas técnicas de administração e organização produtivas, pelas tecnologias a serviço da produção, pelos trabalhadores e empregadores e suas relações de produção. Habermas (1975) encapsula o mundo do trabalho no mundo do sistema. Desse modo, ao seguir uma racionalidade técnica instrumental, o mundo do trabalho seria co-responsável pela fragmentação do mundo da vida provocada pelo mundo sistêmico.

Se o trabalho contribui para a construção do sujeito, de alguma forma ele é produtor de subjetividade. Cabe ao trabalho, então, uma parcela no processo de subjetivação, de transformação do indivíduo em sujeito. Uma vez que o trabalho não é alheio ao mundo da vida, mas coadjuvante da criação e manutenção do mesmo por sua participação no processo de subjetivação do ser humano, por que pertenceria em sua totalidade ao mundo sistêmico? O mundo do trabalho está no mundo do sistema porque segue as orientações políticas e econômicas de uma racionalidade instrumental capitalista que domina a linha de pensamento da sociedade desde o princípio da modernidade. Como também pertence ao mundo da vida por sua incumbência de ser produtor sujeito da subjetividade no homem.

A fragmentação do mundo da vida frente ao mundo sistêmico traz efeitos sobre a sociedade e cria um ambiente de contrastes entre as condições de produção e as condições sociais de vida. $\mathrm{O}$ mundo do trabalho está ameaçado pela dominação do mundo sistêmico. A racionalidade capitalista subtrai a porção do mundo do trabalho que sobrevivia no mundo da vida. À mercê do mundo sistêmico, o trabalho amplia sua força de dominação sobre o mundo da vida, ao reproduzir a ideologia capitalista e o (a) sujeitamento a um trabalho alienado desprovido de sentido.

A teoria de Touraine (1994) sobre a subjetivação do indivíduo, como meio de equilibrar o mundo dos homens e o mundo da razão capitalista, não considerou o papel estruturante do trabalho. O trabalho que constrói o ser e a sociedade significa, em outras palavras, o trabalho que eleva o indivíduo a sujeito consciente, por sua vez, constrói e modifica o mundo da vida. A retomada de espaço do mundo da vida não depende de uma tomada de consciência individual e solitária do homem, mas de uma conscientização alavancada pelo trabalho e isso não é uma ação individual e isolada. Por esse motivo, há uma correspondência direta entre a recuperação do mundo do trabalho e o da vida.

O trabalhador é habitante dos dois mundos: vida e trabalho. A absorção do mundo do trabalho pelo mundo sistêmico causa ameaças ao "trabalhador-empregado", residente do mundo do trabalho e ao "trabalhador-indivíduo", residente do mundo da vida. Marx, em O capital (2002, p. 443), lança perguntas ainda pertinentes no início do século XXI. Quando percebe o aumento da produtividade do trabalho pela utilização de técnicas de organização produtiva, administração, ciências e máquinas tecnológicas, indaga: "essa elevada produtividade não se realiza à custa de maior dispêndio de trabalho?" O crescimento da produção em um tempo e custo cada vez menores não significa "explorar cada vez mais intensivamente a força de trabalho?" (Idem, p. 479)

Os relatos de trabalhadores da indústria automotiva da Região Metropolitana de Curitiba respondem à dupla questão. A intensificação e sobrecarga de trabalho são experimentadas por todos os entrevistados, sem exceção: "Aumentou muito [a meta]. (...) Nossa! Eu entrei lá [montagem de caminhão] a gente produzia 18 caminhões, agora, tipo agora eles estão produzindo quase 40 caminhões".(CINALLI, 2003. Entrevista $n^{\circ} 7$ com Montador de Motores, jan. 2005), "é um trabalho 
agitado. (...) para dar conta do serviço, é, eu tenho dois telefones na minha mesa. Eu criei uma briga lá e peguei dois telefones, um para atender e outro para falar." (CINALLI, 2003. Entrevista $\mathrm{n}^{\circ} 5$ com Analista de Logística, fev. 2005), "Tem que ter rapidez, qualidade, organização. Tudo, sabe? (...) E trabalhamos assim, com rapidez e qualidade. Isso é essencial. Não adianta querer tirar peça com qualidade e demorar uma porção de tempo. Porque não dá, a gente tem que atingir meta. (...) você trabalha teu turno inteiro com aquela preocupação de produção e qualidade, sabe? Tudo junto." (PAIXÃO, 2003, Entrevista n 3 com Monitor da Indústria, set. 2004).

A disseminação institucionalizada de horas extras, a sobrecarga e polivalência do trabalho, o desprezo dos efeitos sobre a saúde e subjetividade do trabalhador, a exigência de qualificações profissionais e educacionais corporificam o avanço do mundo sistêmico sobre o mundo da vidatrabalho. Diante deste cenário, ocorre a relativização não somente do trabalho como posição chave da identidade pessoal e social, mas também do mundo da vida como pano de fundo da sociedade e da existência pública-privada de seus atores.

\section{6. À guisa de conclusão}

Estudiosos contemporâneos procuram uma maneira de conduzir a produção e de obter seus benefícios para a sobrevivência e o prosseguimento da sociedade, sem sofrer os efeitos agressivos do capitalismo sobre o mundo da vida. Habermas (1988) indica a razão comunicativa como um novo paradigma que recupera a subjetividade do indivíduo, pelo entendimento mútuo de ouvintes sobre o mundo objetivo, social e subjetivo, antes negada pelo processo unilateral racional e pelo determinismo econômico-administrativo.

Marcuse (Apud FEENBERG, 2004a) propõe uma nova ciência e tecnologia que busquem a harmonia entre a natureza e o ser humano, ao invés do conflito. Uma visão de natureza parceira, integrada com o homem, onde se usufrui de seus recursos de forma consciente, tratando-a mesmo como um outro sujeito.

Mészáros (2002) aposta na auto-realização do ser humano por meio da riqueza da produção e não pela produção da riqueza alienante e reificada. Admite que a atividade-vital dos indivíduos tem uma finalidade e "pode oferecer uma alternativa viável à cega espontaneidade auto-reprodutiva do capital e suas conseqüências destrutivas. Isto significa a produção e a realização de todas as potencialidades criativas humanas, assim como a reprodução continuada das condições intelectuais e materiais de intercambio social" (Idem, p. 613).

Touraine (1994), por sua vez, promove o surgimento do homem-sujeito com capacidade de transmitir e perceber significado em suas ações. O indivíduo capaz de encarnar o papel de ator social tem o poder de conduzir e transformar as relações sociais do mundo racional moderno mediante sua consciência, liberdade e criatividade, na forma de fragmentos carregados de valores que se opõem e desenham como que a uma

multidão de formigas atreladas à racionalidade técnica, operadores, empregados, técnicos, com posição alta ou baixa, que é levada a não se preocupar com os fins de sua ação. Porque não se pode rodar o filme ao contrário e reencontrar a unidade irremediavelmente partida do mundo das luzes e do progresso; é preciso, portanto, interrogar-se sobre a maneira de restabelecer a unidade entre a vida e o consumo, a nação e a empresa, e entre cada uma delas e o mundo de racionalidade instrumental [grifo dos autores]. Se esta reconstrução é impossível, melhor será então não mais falar de modernidade. (TOURAINE, 1994, p. 230).

A recuperação do trabalho como criador do sujeito é fundamental. Apenas o indivíduosujeito tem condições de reconstruir o trabalho e o mundo da vida, de perceber os contrastes da alta produção, de encarnar-se ator social da mudança e transformar-se em um "ser social". A literatura pertinente desdobra-se em compreender a complexidade dos fenômenos, provando concepções renovadas de espaço e tempo numa era para além da modernidade, de esgotamento da racionalidade instrumental e de limites à acumulação capitalista, como foi marcado o século XX. Autores mais radicais remetem a uma crise estrutural do capital e à necessidade de reconhecer traços das 
determinações do desenvolvimento desigual entre os países avançados e aqueles sob a lógica capitalista dominante. Entre os eventos significativos para essa transição histórica, arrolam-se as experiências estratégicas de desenvolvimento com transferência de tecnologia e afirmação de políticas neoliberais em países da Ásia, da África e da América, o fenômeno do desemprego estrutural crescente, o declínio do Welfare Stare nos países centrais, o endividamento gradativo e interdependente de todos os países e o movimento do capital de caráter cada vez mais financeiro e fluído em direção a países de capitalismo emergente, apostando em grandes investimentos diretos, como os da indústria automobilística que migra para os países de capitalismo emergente.

Neste limiar do século XXI, predomina a ameaça mundial aos interesses da vida em geral, o que para Habermas (1987, p. 104-105) “o empobrecimento estrutural dos países em desenvolvimento, o desemprego e os desequilíbrios sociais crescentes nos países desenvolvidos, problemas com o meio ambiente sobrecarregado, altas tecnologias operadas às raias da catástrofe, dão as palavras-chave que invadiram a consciência pública através dos meios de comunicação de massa". E completa "as respostas dos intelectuais refletem uma perplexidade não menor que a dos políticos". Transpostas essas preocupações como utopias que impulsionam a realidade histórica, para o plano das interpretações, Habermas (1987) considera a mudança de paradigmas da sociedade do trabalho para a sociedade da comunicação. Para ele, a utopia da sociedade do trabalho perdeu a sua capacidade de persuasão, como força estruturadora e socializadora do trabalho abstrato.

Importante marcar que o trabalho abstrato não é uma maneira de reduzir os trabalhos heterogêneos à dimensão comum do tempo, através das relações entre mercadorias do processo de trabalho, mas tem uma existência real na realidade da troca. A abstração que faz do trabalho incorporado, trabalho abstrato, é uma abstração social, um processo real específico do capitalismo. É apenas no processo de troca que os trabalhos heterogêneos se tornam abstratos e homogêneos e que o trabalho privado se revela social. É o mercado que realiza isso e, portanto, não pode haver uma determinação a priori do trabalho abstrato. A troca é então entendida como uma forma do próprio processo de produção. Não só a abstração surge da realidade da troca, como também o trabalho abstrato é trabalho alienado; a troca é o momento de unidade social sob a forma de eqüalização abstrata ou reificação da força de trabalho na qual a subjetividade humana é expropriada, alerta Colletti (1972, apud BOTTOMORE,1988, p.384).

Este texto lança dúvidas à possibilidade de existir uma saída para a racionalidade dominante. Talvez, o seu tom seja pessimista diante do cenário do mundo do trabalho. Haveria outra maneira de se conduzir a produção e obter benefícios para a população, sem que esta sucumba aos efeitos do capitalismo atual sobre o mundo da vida? Seria possível uma união entre a vida e o sistema para a resolução efetiva de problemas no mundo? Poderia o trabalho deixar de ser uma atividade despersonalizada, inorgânica e ser devolvido ao homem, em suas características de construtor do sujeito? Haveria possibilidade do trabalhador ser realmente sujeito do trabalho? O trabalho poderia ser colocado a serviço do homem?

Alguns desses questionamentos são respondidos de forma direta, outros indiretamente. $\mathrm{O}$ mais importante é a crítica que se possa fazer desse processo que aparenta estar "naturalizado", conduz e controla os meios de vida. Fica a impressão de um despertar abrupto para o que acontece no mundo, embora a problemática seja antiga com roupagens novas. Para o mundo do trabalho essas idéias críticas concretizam uma ponte para a construção de um mundo justo e digno aos seres humanos e não apenas racional ou irracional.

\section{Abstract}

The capitalist-instrumental rationality that invades the world of life is argued here under the prism of the labor. The engaged subjectivity of the worker in this process is one of its bigger effect of the technical, technological and scientific transformation occurred in the XX century and available for the capitalist accumulation, over all from the adoption of the flexible methods to organize the production and the labor. The modern automobile industry established in metropolitan region of 
Curitiba, since middle of years 1990, is one of these examples of transition. The intense social transformations that occurred in the last three decades in the world of labor have been provoked by an avalanche of innovations in the organization of the production and the work. The effects of the changes in course expand through different scopes of the society and impose their consequences for the survival and insertion of emergent social groups in the economic life, each time more integrated. The construction of the text rescues the ideas of Weber about a capitalist-instrumental process that enlarge in modernity, presenting the proposal of Habermas about a communicative action as alternative to the consequences of this hegemonic and annihilating logic over the social being. When analyzing the invasion of the world of system on the world of life and the continuity of this process, this paper reflects the relation rational/subjective, placing the question: in the productive conditions of the multinational industries, that incorporate the Paraná's automotive complex, is it ahead of a rational or irrational capitalism, when looking thought the workers' point of view? Theoretical critics and interviews give support to the answers pointed here.

Key words: Labor; Rationality; Word of Life; Subjectivity; Technology.

\section{Referências}

ARAÚJO, S. M. et al. O trabalho subvertido no jogo capitalista: a racionalidade técnica e a lógica social. História: Questões \& Debates, v. 15, n. 29, p. 59-82, ago./dez. 1998.

ARAÚJO, S. M. Movimento sindical e indústria automobilística do Paraná - processo de transição nas relações de trabalho. Projeto individual de pesquisa, Programa de Pós-graduação em Sociologia, UFPR, 2002.

Da natureza do trabalho científico: o fazer ciência e suas implicações práticas ou de como compartilhar uma metodologia. Coletivo de pesquisa GETS, LAGHUR, NUPESPAR, 2005. 13 p. [mimeo].

ARENDT, H. A condição humana. 10. ed. Rio de Janeiro: Forenze Universitária, 2003.

BOTTOMORE, T. (Org.) Dicionário do pensamento marxista. Rio de Janeiro: Zahar, 1988.

BOURDIEU, P. A economia das trocas simbólicas. São Paulo: Perspectiva, 1974.

CARVAlHO, M. G. Tecnologia e sociedade. In: Bastos, J.A.S.L.A. (Org.) Tecnologia \& Interação. Curitiba: CEFETPR, 1998.

CASTElls, M. A sociedade em rede. 3. ed. São Paulo: Paz e Terra, 2000.

CIMBALISTA, S. N. As adversidades do trabalho sob a ótica da produção flexível: um estudo comparativo entre Brasil e Inglaterra. Projeto de pesquisa, Doutorado Interdisciplinar em Ciências Humanas, UFSC, 2005.

CINALLI, D. L. Trabalho, subjetividade, revolução tecnológica e a indústria automotiva do Paraná. Projeto individual de pesquisa, Programa de Pós-graduação em Sociologia, UFPR, 2003.

CORRÊA, M. B. Tecnologia. In: CATTANI, A. (Org). Trabalho e tecnologia: dicionário crítico. Petrópolis: Vozes, 1997. p. $250-257$.

DEJOURS, C. A banalização da injustiça social. Rio de Janeiro: FGV, 2003.

FEENBERG, A. Marcuse or Habermas: two critiques of technology. Disponível em: <http://wwwrohan.sdsu.edu/faculty/feenberg/marhab.html> Acesso em: 28 jan. 2004(a).

Heidegger, Habermas, and the essence of technology. Disponível em: <http://wwwrohan.sdsu.edu/faculty/feenberg/kyoto.html $>$ Acesso em: 20 jan. 2004(b).

GALLINO, L. Dizionario di Sociologia. Torino: TEA, 1993.

GERTH, H. H.; MILLS, W. (org). Ensaios de Sociologia. Rio de Janeiro: Zahar Editores, 1968. 
GORZ, A. Metamorfoses do trabalho; crítica da razão econômica. São Paulo: Annablume, 2003.

HABERMAS, J. Técnica e ciência como ideologia. In: Os Pensadores. São Paulo: Abril Cultural, 1975. p. 303-333.

A nova intransparência: a crise do Estado de bem-estar social e o esgotamento das energias utópicas. Novos Estudos, CEBRAP, n. 18, p. 103-114, set. 1987(a).

Teoria de la accion comunicativa: tomo II, critica de la razón funcionalista. Madrid: Taurus, 1988.

Pensamento pós-metafísico. Rio de Janeiro: Tempo Brasileiro, 1990.

HARVEY, D. Condição pós-moderna: uma pesquisa sobre as origens da mudança social. 11.ed. São Paulo: Loyola, 2002.

MARX, K. O capital: crítica da economia política. 19. ed. Rio de Janeiro: Civilização Brasileira, 2002. v. 1.

Contribuição à crítica da economia política. São Paulo: Martins Fontes, 1977.

MEDEIROS, A. M. S.; Marques, M. Habermas e a teoria do conhecimento. Educação Temática Digital, v. 5, n. 1, p. 1-24, dez. 2003.

MÉSZÁROS, I. Para além do capital: rumo a uma teoria de transição. São Paulo: Boitempo; UNICAMP, 2002.

MUNIZ, J. N. O conhecimento científico como falsa consciência necessária. Cadernos de Ciência \& Tecnologia, Brasília, v. 12, n. 1/3, p. 29-38, 1995.

PAIXÃO, A. A subjetividade no "novo" tempo de trabalho: um estudo sobre a flexibilidade. Projeto individual de pesquisa, UFPR, 2003.

REIS, F. W. Racionalidade não discursiva? Resenha de Jessé Souza, Patologias da modernidade: um diálogo entre Habermas e Weber. Revista Brasileira de Ciências Sociais, v. 14, n. 39, fev. 1999, pp. 177-178.

ROUANET, S. Razão negativa, razão comunicativa. In: . As razões do Iluminismo. São Paulo: Companhia das Letras, 1987,

UNIVERSIDADE FEDERAL DO PARANÁ. Indústria automobilística no Paraná: relações de trabalho e novas territorialidades, Projeto Integrado de Pesquisa, GETS - Grupo de estudos Trabalho e Sociedade, LAGHUR Laboratório de Geografia Humana e Regional, UFPR, 2002.

WEBER, M. Burocracia. In: GERTH, H. H.; MILLS, W. (Orgs.). Ensaios de Sociologia. Rio de Janeiro: Zahar Editores, 1968.

Basic Concepts in sociology. London: Peter Owen, 1978.

A ética protestante e o espírito do capitalismo. São Paulo: Martin Claret, 2002. 